\title{
Role of selective progesterone receptor modulators in the treatment of symptomatic uterine fibroids
}

\author{
Neha Naresh*, Poonam Mani, Lalita Yadav, Nidhi Singh
}

Department of Obstetrics and Gynecology, Subharti Medical College, Meerut, Uttar Pradesh, India

Received: 28 May 2020

Accepted: 16 June 2020

\section{*Correspondence:}

Dr. Neha Naresh,

E-mail: dr.nehanaresh@gmail.com

Copyright: () the author(s), publisher and licensee Medip Academy. This is an open-access article distributed under the terms of the Creative Commons Attribution Non-Commercial License, which permits unrestricted non-commercial use, distribution, and reproduction in any medium, provided the original work is properly cited.

\begin{abstract}
Background: Uterine leiomyomas are benign tumours of smooth muscle cells and fibrous tissue that develop within the wall of the uterus. Objective of this study was to compare efficacy and safety of Mifepristone and Ulipristal acetate in the treatment of symptomatic uterine fibroids.

Methods: The present randomized comparative prospective study was conducted among 120 non-pregnant and nonlactating females of age 25-50 years with symptomatic fibroids reported in the department of obstetrics and gynecology, Chhatrapati Shivaji Subharti Hospital, Meerut, Uttar Pradesh for a duration of 2 years from September 2017 to July 2019.The selected subjects were divided into two treatment arms i.e. Group 1: ulipristal acetate: $5 \mathrm{mg}$ OD for 3 months and Group 2: mifepristone: $25 \mathrm{mg}$ OD for 3 months. Detailed history of the patient, general physical examination and systemic examination was done followed by per abdomen examination, per speculum and per vaginal examination. A blood examination, USG (pelvis), Pap smear and endometrial biopsy was done. Subjects visited the hospital at visit 1, visit 2, visit 3, visit 4, visit 5 and visit 6 for 6 months.

Results: In both the groups, maximum subjects were in the age group of 36-40 years, followed by 41-50 years. When mean PBAC score at first, second, third, fourth and fifth visit was compared statistically among ulipristal acetate and mifepristone group, it was found to be statistically significant. Uterine pain was reduced more in mifepristone group as compared to ulipristal acetate group at all the different intervals. Size was reduced more in mifepristone group as compared to ulipristal acetate group at all the different intervals.

Conclusions: Authors conclude from this study that mifepristone should be preferred over ulipristal acetate for treatment of symptomatic fibroids.
\end{abstract}

Keywords: Fibroid uterus, Heavy menstrual bleeding, Mifepristone, Ulipristal acetate

\section{INTRODUCTION}

Uterine leiomyomas are benign tumours of smooth muscle cells and fibrous tissue that develop within the wall of the uterus. ${ }^{1}$ They may grow as a single tumor or in clusters and one such single fibroid can measure up to $20 \mathrm{~cm}$ or more and may range in size from seedlings to large uterine tumors. ${ }^{2}$ Uterine fibroids (UFs) are the most frequent tumor of the female genital tract with an increasing frequency during the women's fertile years with a prevalence of $20-77 \%$ depending on the population and method of assessment. ${ }^{3-5}$ Its incidence increases with increasing age and the life time risk for women to develop uterine fibroids is $70 \%{ }^{6}$ Uterine fibroids $(65 \%)$ are attributed to inadequate endometrial receptivity to embryo implantation secondary to deleterious effects of uterine fibroids on endometrium. ${ }^{7}$ Many women, if given the option, would prefer medical treatment for their uterine fibroids over a surgical solution to avoid the possible risks associated with surgery, and preserve their uterus for future fertility and also for psychological/feminine reasons. ${ }^{8}$ 
Surgical interventions include hysterectomy and myomectomy. ${ }^{9,10}$ Other less invasive procedure include uterine artery embolization and magnetic resonance guided focused ultrasound surgery (MRgFUS). ${ }^{11}$ Various medical therapies used for fibroids include tranexamic acid, combined oral contraceptive pills, GnRH analogues, selective estrogen and progesterone receptor modulators, somatostatin analogues and aromatase inhibitors. ${ }^{12}$

Owing to their pharmacological properties, SPRMs have been tested or are under development in the indication of uterine fibroids. Ulipristal acetate is the only molecule which has received marketing authorization for a presurgical 3-month treatment of uterine fibroids. Three other SPRM have been tested for the indication of uterine fibroids: mifepristone, asoprisnil and telapristone acetate. ${ }^{13}$ The most commonly used progesterone receptor modulator is mifepristone (RU486). It binds strongly to endometrial progesterone receptors, minimally to oestrogen receptors and up regulates androgen receptors. It has been shown to decrease myoma size as well as symptoms. ${ }^{14}$ Use of mifepristone and ulipristal acetate individually has been studied by some researchers but comparative studies of these 2 drugs have rarely been done. For this reason, authors have conducted this study to compare efficacy and safety of mifepristone and ulipristal acetate in the treatment of symptomatic uterine fibroids.

\section{METHODS}

The present randomized comparative prospective study was conducted among 120 non-pregnant and nonlactating females of age 25-50 years with symptomatic fibroids reported in the department of obstetrics and gynecology, Chhatrapati Shivaji Subharti Hospital, Meerut, Uttar Pradesh for a duration of 2 years from September 2017 to July 2019. The study protocol for all procedures was approved by the Institutional review board for ethical clearance and was performed in accordance with the code of ethics of the World Medical Association according to the Declaration of Helsinki of 1975, as revised in 2000. All patients were asked to sign a written consent form prior to inclusion in the study. The subjects were selected according to the following inclusion and exclusion criteria.

\section{Inclusion criteria}

Women between 25-50 years, body mass index (BMI) of $18-35 \mathrm{~kg} / \mathrm{m}^{2}$, subjects with symptomatic fibroid, uterine size equivalent to that of a pregnancy of no more than 16 weeks of gestation, uterine fibroid not more than $10 \mathrm{~cm}$ in diameter and no significant findings on clinical breast examination.

\section{Exclusion criteria}

Pregnant and lactating women, women desirous of pregnancy, genital bleeding of unknown etiology, uterine, cervical, ovarian or breast cancer, hemoglobinopathy (sickle cell anemia, thalassemia), coagulation disorders, $\mathrm{Hb} \leq 6 \mathrm{gm} / \mathrm{dl}$, history of endometrial ablation or uterine artery embolization for myoma, women with history of current treatment for myoma with any drug like GnRH Agonist, women with history of hormonal intake in last 2 months, women with history of hormonal contraception intake in last 2 months, known case of hepatic or renal impairment, neurological disease, endocrinal disease or severe asthma and women with heavy menstrual bleeding in preceding cycle.

\section{Study groups}

The selected subjects were divided into two treatment arms i.e. Group 1: ulipristal acetate: $5 \mathrm{mg}$ OD for 3 months and Group 2: mifepristone: $25 \mathrm{mg}$ OD for 3 months. As per FIGO classification of fibroids, they are classified into various classes like intramural, submucosal, intramural type and further helps in its mode of treatment and the treatment's efficacy.

Detailed history of the patient, general physical examination and systemic examination like central nervous system, respiratory system, cardio-vascular system was done followed by per abdomen examination, per speculum and per vaginal examination. In per vaginal examination, the position, size, shape, mobility and consistency of uterus along with bilateral adnexa were noted. Detailed menstrual and obstetric history was recorded. At each visit, examination of the patient was done. PBAC score and universal pain assessment score was explained to all participants to be recorded during study period. Complete hematological with biochemical screening was done including haemoglobin, hematocrit, total leucocyte count, differential leucocyte count and ESR. Pap smear and endometrial sampling was done at the time of recruitment.

\section{Examination}

At $1^{\text {st }}$ visit, general, systemic and pelvic examinations were done, pregnancy was excluded and sample was taken for investigations. Clinical examination i.e. per speculum and per vaginum was done in every visit. The reports were reviewed before recruitment of the patients. Baseline ECG and USG (Abd/TVS) of every patient was done. USG was done in every visit and changes were noted in size of fibroid and uterus, volume of fibroid, ET of uterus, vascularity etc.

\section{Study visits}

Subjects visited the hospital at visit 0 (for evaluation and tests to screen the patients for study), visit 1 (after one week for recruitment and for initiation of treatment), visit 2 (after 1 month for assessment of PBAC score and improvement in symptoms, if any), visit 3 (after 2 months for assessment of PBAC score and improvement in symptoms if any), visit 4 (after 3 months for evaluation 
of patient), visit 5 (after 4 months for follow-up) and visit 6 (after 6 months for follow-up).

\section{Statistical analysis}

Data so collected was tabulated in an excel sheet, under the guidance of statistician. The means and standard deviations of the measurements per group were used for statistical analysis (SPSS 22.00 for windows; SPSS inc, Chicago, USA). Difference between two groups was determined using student t-test as well as Chi-square test and the level of significance was set at $\mathrm{p}<0.05$.

\section{RESULTS}

A total of 64 and 66 patients gave consent for ulipristal and mifepristone treatment respectively. No. of subjects drop outs in subsequent visits were 4 and 6 in for Ulipristal and Mifepristone group respectively. Finally, 60 patients were left in both the groups as shown in Figure 1. In both the groups, maximum subjects were in the age group of 36-40 years, followed by 41-50 years. The mean age of the study subjects was $37.58 \pm 6.41$ in ulipristal group and $36.65 \pm 6.22$ in mifepristone group respectively (Figure 2). In this study, $41.7 \%$ of the subjects in ulipristal acetate as well as mifepristone group were post-graduates. Graduation was done by $35 \%$ in ulipristal and $51.7 \%$ in mifepristone group.

PBAC improvement was found in both the study groups at different intervals, but it was comparatively more in mifepristone group. However, few patients in both the groups have experienced amenorrhoea. When mean PBAC score at first, second, third, fourth and fifth visit was compared statistically among ulipristal acetate and mifepristone group, it was found to be statistically significant as $\mathrm{p}<0.05$ (Table 1 ).

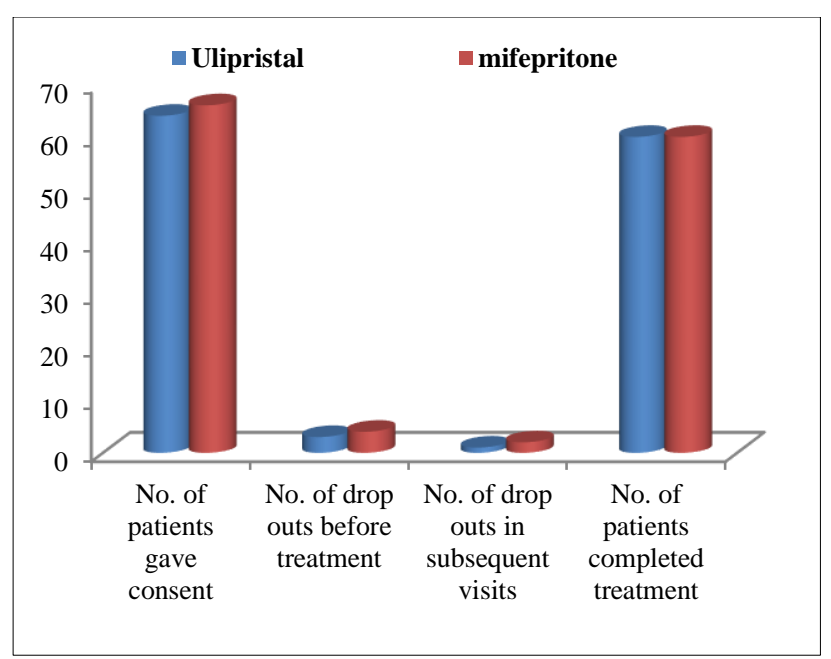

Figure 1: Follow-up of patients.

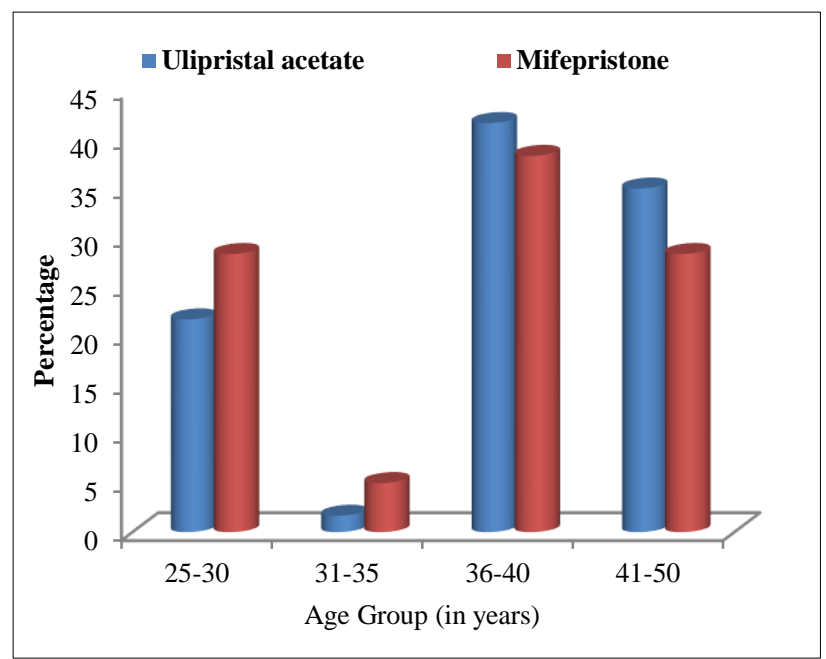

Figure 2: Age distribution of the study groups.

Table 1: Comparison of PBAC score at different visit among the study groups.

\begin{tabular}{|lllllll|l|l|}
\hline \multirow{2}{*}{ PBAC score } & \multicolumn{2}{l}{ Ulipristal acetate } & \% improvement & \multicolumn{2}{l|}{ Mifepristone } & \% improvement & t-test & p-value \\
\cline { 2 - 10 } & Mean & SD & & Mean & SD & & & \\
\hline Before & 202.65 & 25.28 & & 204.61 & 23.41 & & 1.20 & 0.19 \\
\hline First & 174.38 & 19.37 & $13.95 \%$ & 161.19 & 23.41 & $21.22 \%$ & 7.81 & $<0.01 *$ \\
\hline Second & 154.18 & 20.83 & $23.91 \%$ & 131.39 & 18.49 & $35.78 \%$ & 10.92 & $<0.01 *$ \\
\hline Third & 137.62 & 22.71 & $32.09 \%$ & 119.14 & 19.55 & $41.77 \%$ & 6.75 & $0.02 *$ \\
\hline Fourth & 126.48 & 18.43 & $37.59 \%$ & 108.89 & 17.31 & $46.78 \%$ & 13.14 & $<0.01 *$ \\
\hline Fifth & 112.89 & 16.30 & $44.29 \%$ & 101.71 & 17.89 & $50.29 \%$ & 10.64 & $<0.01 *$ \\
\hline
\end{tabular}

*statistically significant.

Uterine pain was reduced more in mifepristone group as compared to ulipristal acetate group at all the different intervals. When mean uterine pain assessment at first, second, third, fourth and fifth visit was compared statistically among ulipristal acetate and mifepristone group, it was found to be statistically significant as $\mathrm{p}<0.05$ (Table 2).
Size was reduced more in mifepristone group as compared to ulipristal acetate group at all the different intervals, though it was statistically insignificant as p>0.05 (Table 3). Increase in ET was found in both the study groups at different intervals. When mean ET at fifth visit was compared statistically among ulipristal acetate 
and mifepristone group, it was found to be statistically significant as $\mathrm{p}<0.05$ (Table 4).
Figure 3 shows that $100 \%$ of the subjects were satisfied with the treatment in both the groups.

Table 2: Comparison of uterine pain assessment at different visit among the study groups.

\begin{tabular}{|lllllllll|}
\hline \multirow{2}{*}{$\begin{array}{l}\text { Uterine pain } \\
\text { assessment }\end{array}$} & \multicolumn{2}{l}{ Ulipristal acetate } & \% improvement & \multicolumn{2}{l}{ Mifepristone } & \% improvement & t-test & p-value \\
\hline Before & Mean & SD & & Mean & SD & & & \\
\hline First & 8.83 & 2.81 & & 8.72 & 2.29 & & 0.42 & 0.59 \\
\hline Second & 6.68 & 2.47 & $24.34 \%$ & 5.91 & 1.92 & $32.22 \%$ & 1.57 & $0.04^{*}$ \\
\hline Third & 5.11 & 2.16 & $42.13 \%$ & 4.07 & 1.98 & $53.33 \%$ & 2.79 & $0.02^{*}$ \\
\hline Fourth & 4.28 & 1.91 & $51.53 \%$ & 3.43 & 1.67 & $60.67 \%$ & 2.60 & $0.03^{*}$ \\
\hline Fifth & 3.73 & 1.98 & $57.76 \%$ & 2.90 & 1.79 & $66.74 \%$ & 1.34 & 0.11 \\
\hline
\end{tabular}

Table 3: Comparison of size (volume) of fibroid among the study groups at different visits.

\begin{tabular}{|lllllllll|}
\hline \multirow{2}{*}{ Size } & Ulipristal acetate & \% Improvement & \multicolumn{2}{l|}{ Mifepristone } & \% Improvement & t-test & p-value \\
& Mean & SD & & Mean & SD & & 1.16 & 0.22 \\
\hline Before & 3.86 & 1.69 & & 4.11 & 1.68 & & 0.27 & 0.58 \\
\hline First & 3.52 & 1.34 & $24.34 \%$ & 3.37 & 1.28 & $32.22 \%$ & 0.40 & 0.57 \\
\hline Second & 3.04 & 1.27 & $42.13 \%$ & 2.81 & 1.07 & $53.33 \%$ & 0.97 & 0.28 \\
\hline Third & 2.79 & 1.35 & $27.72 \%$ & 2.48 & 1.52 & $39.66 \%$ & 1.03 & 0.24 \\
\hline Fourth & 2.47 & 1.40 & $36.01 \%$ & 2.19 & 1.30 & $46.72 \%$ & 1.29 & 0.10 \\
\hline Fifth & 2.30 & 1.57 & $40.41 \%$ & 2.04 & 1.37 & $50.36 \%$ & & \\
\hline
\end{tabular}

Table 4: Comparison of endometrial thickness (ET) among the study groups at different visits.

\begin{tabular}{|lllllllll|}
\hline & \multicolumn{2}{l}{ Ulipristal acetate } & \% Increment & \multicolumn{2}{l}{ Mifepristone } & \% Increment & t-test & p-value \\
& Mean & SD & & Mean & SD & & 0.81 & 0.62 \\
\hline Before & 13.85 & 0.29 & & 13.06 & 1.29 & & 0.59 & 0.48 \\
\hline First & 15.32 & 1.09 & $10.61 \%$ & 14.40 & 1.18 & $10.26 \%$ & 0.39 \\
\hline Second & 16.76 & 1.01 & $21.01 \%$ & 15.71 & 1.37 & $20.29 \%$ & 0.98 & 0.34 \\
\hline Third & 17.23 & 1.32 & $24.40 \%$ & 16.09 & 1.78 & $23.20 \%$ & 1.22 & 0.09 \\
\hline Fourth & 17.59 & 1.41 & $27.00 \%$ & 16.78 & 1.91 & $28.48 \%$ & 0.91 & 0.29 \\
\hline Fifth & 18.41 & 1.69 & $32.92 \%$ & 17.32 & 1.70 & $32.62 \%$ & 1.54 & $0.04 *$ \\
\hline
\end{tabular}

*statistically significant.

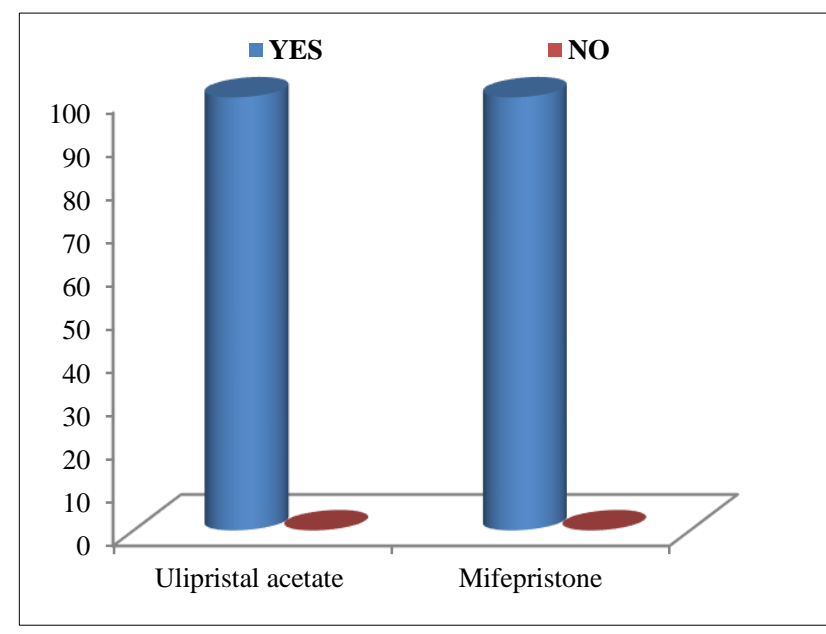

Figure 3: Satisfaction level in both groups.

\section{DISCUSSION}

Progesterone is one of the key players in the female reproductive function. In the uterus, progesterone regulates the growth and differentiation of endometrial and myometrial cells, and is therefore a counter player to estrogen. Progesterone may have inhibitory and stimulatory effects on cell proliferation. ${ }^{15}$ Selective progesterone receptor modulators (SPRMs) like mifepristone and ulipristal acetate have been used for the treatment of dysfunctional uterine bleeding and uterine myomas because of their anti-proliferative effects on endometrium and myometrium. ${ }^{16}$

Mean PBAC score was 202.65 and 204.61 in ulipristal acetate and mifepristone group respectively before the intervention and after intervention at fifth visit, the score was 112.89 and 101.71 in ulipristal acetate and 
mifepristone group respectively. PBAC improvement was found in both the study groups at different intervals, but it was comparatively more in Mifepristone group. A study conducted by Arora CD et al, it was seen that with mifepristone all patients without exception had amenorrhea bringing the PBAC score to 'zero'. ${ }^{17}$ In one more study conducted by Shradha et al, patients out of 50 became amenorrhea, and there is no patient with menorrhagia at the end of treatment. ${ }^{18}$ Therefore, Mifepristone is a reasonable choice of treatment in perimenopausal age group and patients who want to avoid surgery.

In the present study mean pain score was 8.83 and 8.72 in ulipristal acetate and mifepristone group respectively before the intervention and after intervention at fifth visit, the score was 3.14 and 2.57 in ulipristal acetate and mifepristone group respectively. Pain improvement was found in both the study groups at different intervals, but it was comparatively more in mifepristone group. Kale AR in his study found ulipristal acetate and mifepristone, in women with symptomatic fibroids were associated with decreased pain. ${ }^{19}$ It was observed that mifepristone was more effective in reducing pain than ulipristal acetate in patients having fibroid size of less than $3 \mathrm{~cm}$.

In the present study ET improvement was found in both the study groups at different intervals, but it was comparatively more in mifepristone group. Similar results were reported by Seth $\mathrm{S}$ et al, who revealed that endometrial thickness (ET) at start of treatment was $7.6 \pm 2.8$ which progressively increased in all ' 82 ' cases during the treatment phase with mean $51.9 \%$ rise over three months. ${ }^{20}$

In the present study, mean fibroid size reduction was found in both the study groups at different intervals, but it was comparatively more in mifepristone group. Kale AR revealed that mifepristone was associated in reduction in size of fibroids by $55 \%$ and $40 \%$ in patients having fibroid size of more than $3-5 \mathrm{~cm}$ and less than $3 \mathrm{~cm}$ respectively. ${ }^{19}$ Feng C21 in their comparative study of women with symptomatic uterine fibroids who were treated with $5 \mathrm{mg}$ or $2.5 \mathrm{mg}$ of mifepristone or placebo found that treatment with mifepristone was associated with significant improvement in health-related quality of life.

Funding: No funding sources Conflict of interest: None declared Ethical approval: Not required

\section{REFERENCES}

1. Munro MG, Critchley HO, Broder MS, Fraser IS FIGO Working group on menstrual disorders. FIGO classification system (PALM-COEIN) for causes of abnormal uterine bleeding in nongravid women of reproductive age. Int $\mathbf{J}$ Gynaecol Obstet. 2011;113(1):3-13.
2. Lumsden MA, Wallace EM. Clinical presentation of uterine fibroids. Baillieres Clin Obstet Gynaecol. 1998;12:177-95.

3. Cramer SF, Patel A. The frequency of uterine leiomyomas. Am J Clin Pathol. 1990;94(4):435-8.

4. Marshall LM, Spiegelman D, Barbieri RL. Variation in the incidence of uterine leiomyoma among premenopausal women by age and race. Obstet Gynecol. 1997;90(6):967-73.

5. Vollenhoven B. Introduction: the epidemiology of uterine leiomyomas. Baillieres Clin Obstet Gynaecol. 1998;12(2):169-76.

6. Baird DD, Dunson DB, Hill MC, Cousins D, Schectman JM. High cumulative incidence of uterine leiomyoma in black and white women: ultrasound evidence. Am J Obstet Gynecol. 2003;188(1):100-7.

7. Olive DL, Pritts EA. Fibroids and reproduction. Semin Reprod Med. 2010;28(3):218-27.

8. Donnez J, Dolmans MM. Uterine fibroid management: from the present to the future. Human Reprod Update. 2016;22(6):665-86.

9. Williams AR. Uterine fibroids-what's new? F1000Res. 2017;6.

10. Khan AT, Shehmar M, Gupta JK. Uterine fibroids: current perspectives. Int $\mathrm{J}$ Women's Health. 2014;6:95.

11. Han NL, Ong CL. Magnetic resonance-guided focused ultrasound surgery (MRgFUS) of uterine fibroids in Singapore. Ann Acad Med Singapore. 2014;43(11):550-8.

12. Song H, Lu D, Navaratnam K, Shi G. Aromatase inhibitors for uterine fibroids. Cochrane Database Syst Rev. 2013;10:CD009505.

13. Wiehle R. Effects of a new progesterone receptor modulator, CDB-4124, on fibroid size and uterine bleeding. US Obstet Gynecol. 2008;3(1):17-20.

14. Engman M, Granberg S, Williams AR. Mifepristone for treatment of uterineleiomyoma. A prospective randomized placebo-controlled trial. Hum Reprod. 2009;24(8):1870-9.

15. Bestel E, Donnez J. The potential of selective progesterone receptor modulators for the treatment of uterine fibroids. Expert Rev Endocrinol Metab. 2014;9(1):79-92.

16. Wozniak S, Szkodziak P, Czuczwar P. The effect of ulipristal acetate treatment on symptomatic uterine fibroids within 12-months follow-up. Przegla d Menopauzalny Menopause Rev. 2014;13(1):18-21.

17. Arora D, Chawla J, Kochar SP, Sharma JC. A randomized control trial to assess efficacy of Mifepristone in medical management of uterine fibroid. Med J Arm Forces India. 2017;73(3):267-73.

18. Shradha AK, Sahay PB. Role of Mifepristone in medical management of uterine fibroid. J Obst Gyn India. 2002;52(5):52-3.

19. Kale AR. Comparison between mifepristone and ulipristal acetate as an alternative to surgical management of uterine fibroids (leiomyoma) in symptomatic patients of reproductive age group in 
Asian population. Int $\mathrm{J}$ Reprod Contracept Obstet Gynecol. 2018;7:109-13.

20. Seth S, Goel N, Singh E, Mathur AS, Gupta G. Effect of mifepristone $(25 \mathrm{mg})$ in treatment of uterine myoma in perimenopausal woman. J Mid-life Health. 2013;4:22-6.

21. Feng C, Meldrum S, Fiscella K. Improved quality of life is partly explained by fewer symptoms after treatment of fibroids with mifepristone. Int $\mathrm{J}$ Gynaecol Obstet. 2010;109(2):121-4.

Cite this article as: Naresh N, Mani P, Yadav L, Singh N. Role of selective progesterone receptor modulators in the treatment of symptomatic uterine fibroids. Int J Reprod Contracept Obstet Gynecol 2020;9:2703-8. 